\title{
Determining the Composition of Imported Recycled Plastics with Differential Scanning Calorimetry
}

\author{
ChuanLuo ${ }^{1}$, ChaoZhang ${ }^{2}$, ShanHaoXu ${ }^{1}$, HaoWang ${ }^{1}$, YinZhang ${ }^{2}$ and LifengYuan ${ }^{3 *}$ \\ ${ }^{1}$ Ningbo Customs District, QinYi Road 66\#, NingBo, 315012, P. R. China \\ ${ }^{2}$ Ningbo academy of science and technology for inspection and quarantine, QinYi Road 66\#, NingBo, 315012, P. R. China \\ ${ }^{3}$ Joysun Testing service, QinYi Road 66\#, NingBo, 315012, P.R. China
}

\begin{abstract}
The analysis of the composition of recycled plastics is the prerequisite for identifying the properties of recycled plastics goods-solid waste. This paper systematically studies the composition of crystalline polymers by differential scanning calorimetry, and studies the common blends of polyethylene and polypropylene. The composition of polyamide 6 and polyamide 66 blends, polyethylene and polyamide blends and other common recycled plastics. The standard enthalpy value method and the melting enthalpy area normalization method are compared. The conclusion is that the melting enthalpy area normalization method is more beneficial Determine the composition of recycled plastics. For polyethylene/polypropylene blends, the repeatability of polyethylene and polypropylene should not exceed $5 \%$; for polyamide $6 /$ polyamide 66 blends, the repeatability of polyamide should not exceed 5\%. More than $3 \%$; For blends of polyethylene and polyamide, the repeatability of polyethylene and polyamide should not exceed $6 \%$.
\end{abstract}

\section{Introduction}

The plastic industry is a pillar industry of the national economy, but it's difficult to recycle though it's easy to use. Recycled plastic is a green industry encouraged and advocated by national policies, and it is also an important field where the entire society works on to reduce and recycle a large amount of plastic solid waste. However, the recycling and reuse of plastic waste is a complicated process. Industrialization, large-scale construction and technological innovation are the trends of the development of the recycled plastic industry. In the early days, China imported a large amount of plastic waste to supplement the shortage of raw materials. In recent years, due to the changes in our country's environmental protection and development policies, the import of plastic waste has been banned. Instead, recycled plastic particles were imported and the amount increased significantly. However, the solid waste properties of the recycled plastic particles are unknown and there is no criterion for this yet, which has caused a backlog of cargo in the port, and companies have complained bitterly. Therefore, there is an urgent need to conduct research in this area now.

According to the statistics related to imported recycled plastics and researches on recycled plastics production and recycling industry, except for the intentional blending and modification, it's extremely difficult to separate polyethylene and polypropylene, polyamide 6 and polyamide 66 in the production process of the recycled plastics. The composition identification of recycled plastics is a key indicator to classify the recycled plastics and evaluate the performance. The composition of recycled plastic particles will also be required in the upcoming national standard for recycled plastics.

The polymer composition tests are mainly qualitative tests, like Yang and Zhang ${ }^{[1,2]}$ et al. used pyrolysis gas chromatography and DSC melting point test to determine the content of each component in the PA6 and PA66 blends, Yuan and Zhang et al. ${ }^{[3,4]}$ used pyrolysis gas chromatography mass spectrometry with solid dispersion method to determine the composition of PC/ABS blends and PA6/PA66 blends, Zhou ${ }^{[5]}$ et al. used IR and DSC in combine to identify the plastic materials, etc. Most of these tests are based on qualitative identification, quantitative tests are less common. And part of the quantitative analysis is based on the comparison with standard samples, which is impossible for recycled plastics with complex sources, as no relevant standards for polymer composition can be queried. Therefore, it is necessary to develop a method to identify the composition of recycled plastics.

\section{Experimental part}

\subsection{Instruments and reagents}

Equipment: Differential Scanning Calorimeter (Switzerland METTLER TOLEDO, DSC 3+), 40ul standard aluminum crucible (domestic), In standard material (Switzerland METTLER TOLEDO), Sn standard material (Switzerland METTLER TOLEDO), high purity nitrogen.

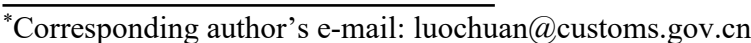


Test procedure: Refer to the GB/T 19466.3-2004 ${ }^{[6]}$ and GB/T 19466.3-2004 ${ }^{[7]}$ standard, establish the temperature program, and refer to related documents. Generally speaking, the higher the heating rate, the sharper the peak shape, but also the higher the initial melting temperature. Choose the heating and cooling rate of $10^{\circ} \mathrm{C} / \mathrm{min}$ considering the time efficiency, the sample size is $5 \mathrm{mg} \pm$ $1 \mathrm{mg}$, and the sample thickness is $0.7 \mathrm{~mm} \pm 0.1 \mathrm{~mm}$.

The heating program is as follows: $50^{\circ} \mathrm{C}$, heat to $280^{\circ} \mathrm{C}$ at a rate of $10^{\circ} \mathrm{C} / \mathrm{min}$, stay constant for $2 \mathrm{~min}$, cool to $50^{\circ} \mathrm{C}$ at a rate of $10^{\circ} \mathrm{C} / \mathrm{min}$, stay constant for $2 \mathrm{~min}$, and then heat to $280^{\circ} \mathrm{C}$ at a rate of $10^{\circ} \mathrm{C} / \mathrm{min}$ again, stay constant for $2 \mathrm{~min}$, and cool down to $50^{\circ} \mathrm{C}$ at a rate of $10^{\circ} \mathrm{C} / \mathrm{min}$.

Select the sample, flatten it to $(0.7 \pm 0.1) \mathrm{mm}$, cut a sample of $(5.0 \pm 1.0) \mathrm{mg}$, put it into a $40 \mathrm{ul}$ standard aluminum crucible, punch the lid, press it, and perform the DSC test according to the above mentioned procedure. Select the melting peak of the second heating section after eliminating the thermal history for analysis.

\section{Results and discussion}

\subsection{Choose polyethylene in the mixture}

Common polyethylene includes low-density polyethylene (LDPE), linear low-density polyethylene (LLDPE), and high-density polyethylene (HDPE). These three types of polyethylene differ in their polymerization patterns, density, molecular weight and the distribution. According to the literature, the thermal properties of different polyethylene have little difference. It can be seen from the discussion about mass and enthalpy in section 2.4 that the enthalpy of LLDPE has a linear relationship with mass. According to the conditions in section 2.4, select three different polyethylene types to test. The results are shown in Table 1:

Table 1 The relationship between the mass and enthalpy of three kinds of polyethylene

\begin{tabular}{cccccc}
\hline No. & 1 & 2 & 3 & 4 & 5 \\
\hline LDPE, m, mg & 0.98 & 2.01 & 5.05 & 5.98 & 8.99 \\
Melting Enthalpy & 97.51 & 189.41 & 441.13 & 544.69 & 754.84 \\
LDPE standard Melting Enthalpy & 99.50 & 94.23 & 87.35 & 91.09 & 83.96 \\
\hline LLDPE, m, mg & 0.95 & 1.99 & 4.95 & 5.93 & 8.94 \\
Melting Enthalpy & 81.4 & 175.8 & 481.88 & 537.24 & 807.43 \\
LLDPE standard Melting Enthalpy & 85.68 & 88.34 & 97.35 & 90.60 & 90.32 \\
\hline HDPE, m, mg & 1.00 & 1.95 & 5.04 & 6.00 & 9.05 \\
Melting Enthalpy & 113.82 & 210.01 & 522.07 & 611.22 & 921.51 \\
HDPE standard Melting Enthalpy & 113.82 & 107.70 & 103.58 & 101.87 & 101.82 \\
\hline
\end{tabular}

It can be seen that the enthalpy values of three kinds of polyethylene are linearly related to the mass. Considering that the melting temperature and enthalpy value of LLDPE are between LDPE and HDPE, and the sample size is large, LLDPE is selected as the polyethylene to prepare the standard samples. Polyethylene (PE) not specified below refers to linear lowdensity polyethylene (LLDPE).

\subsection{Determination of polyethylene and polypropylene content in imported recycled plastics}

Generally, there are two ways to determine the content of each polymer composition in the multi-component blended plastic solid waste, namely the standard enthalpy method and the melting enthalpy normalization method. The standard enthalpy method uses the standard enthalpy value of each polymer to calculate the content of each component in the sample and the melting enthalpy normalization method uses normalization to calculate the content of each component by measuring the melting enthalpy value of each component in the sample.

Select polymers like PE, PP, PA6, PA66 etc., randomly select 5 particles, put them into a $40 \mathrm{ul}$ standard aluminum crucible, punch the lid, and press it. Using the above mentioned method, select the melting peak of the second heating section, normalize the mass and the results are shown in Table 2:

Table 2 Standard melting enthalpy of different polymers

\begin{tabular}{cccccccc}
\hline Polymer & 1 & 2 & 3 & 4 & 5 & AVG. & RSD. \\
\hline PE & 477.41 & 483.73 & 497.67 & 497.18 & 495.98 & 490.39 & $1.89 \%$ \\
PP & 504.23 & 484.69 & 450.03 & 421.24 & 459.50 & 463.94 & $6.89 \%$ \\
PA6 & 336.18 & 334.13 & 333.54 & 336.94 & 316.66 & 331.49 & $2.54 \%$ \\
PA66 & 358.51 & 350.39 & 357.39 & 358.08 & 334.04 & 351.68 & $2.96 \%$ \\
\hline
\end{tabular}

Weigh a certain amount of PE/PP particles, mix and dissolve them with toluene heating reflux. Pour the dissolved poly-PE/PP mixed solution into a watch glass while it's still hot, and place it in a fume cupboard to evaporate until it is completely dry. Then put it into a blast 
oven and dry at $110^{\circ} \mathrm{C}$. The composition and ratio of each standard mixture are shown in Table 3:

Table 3 PE/PP standard mixture composition

\begin{tabular}{ccccccccc}
\hline No. & Item & PE, g & PP, $g$ & $\begin{array}{c}\text { Total mass } \\
\mathrm{g}\end{array}$ & $\begin{array}{c}\text { Percent of PE } \\
\%(\mathrm{~m} / \mathrm{m})\end{array}$ & $\begin{array}{c}\text { Percent of PP } \\
\% \%(\mathrm{~m} / \mathrm{m})\end{array}$ & $\begin{array}{c}\text { Melting } \\
\text { Enthalpy } \\
\text { of PE }\end{array}$ & $\begin{array}{c}\text { Melting } \\
\text { Enthalpy } \\
\text { of PP }\end{array}$ \\
\hline 1 & PE/PP R1 & 0.56 & 4.48 & 5.04 & 11.11 & 88.89 & 29.84 & 385.86 \\
2 & PE/PP R2 & 1.09 & 3.98 & 5.07 & 21.50 & 78.50 & 97.53 & 325.87 \\
3 & PE/PP R3 & 2.04 & 3.03 & 5.07 & 40.24 & 59.76 & 165.42 & 245.50 \\
4 & PE/PP R4 & 2.44 & 2.49 & 4.93 & 49.49 & 50.51 & 225.30 & 223.78 \\
5 & PE/PP R5 & 2.97 & 2.10 & 5.07 & 58.58 & 41.42 & 258.98 & 169.82 \\
6 & PE/PP R6 & 3.99 & 0.93 & 4.92 & 81.10 & 18.90 & 401.53 & 74.90 \\
7 & PE/PP R7 & 4.52 & 0.55 & 5.07 & 89.15 & 10.85 & 451.17 & 44.26 \\
\hline
\end{tabular}

According to the above mentioned standard method, test each standard sample, and use the standard enthalpy method and the melting enthalpy normalization method respectively to calculate the proportion of each composition in the PE/PP blend. The results are shown in Table 4:

Table 4 PE/PP standard mixture composition test results

\begin{tabular}{|c|c|c|c|c|c|c|c|c|c|c|}
\hline \multirow{3}{*}{$\begin{array}{l}\text { Standard } \\
\text { mixture }\end{array}$} & \multicolumn{2}{|c|}{ Actual ratio } & \multicolumn{4}{|c|}{ Standard enthalpy method } & \multicolumn{4}{|c|}{ Melting enthalpy normalization method } \\
\hline & \multirow{2}{*}{ PE } & \multirow{2}{*}{ PP } & \multicolumn{2}{|c|}{ PE } & \multicolumn{2}{|c|}{ PP } & \multicolumn{2}{|c|}{$\mathrm{PE}$} & \multicolumn{2}{|c|}{$\mathrm{PP}$} \\
\hline & & & test & Def. & test & Def. & test & Def. & test & Def. \\
\hline PE/PP R1 & $11.11 \%$ & $88.89 \%$ & $6.09 \%$ & $5.02 \%$ & $83.18 \%$ & $5.71 \%$ & $7.18 \%$ & $3.93 \%$ & $92.82 \%$ & $-3.93 \%$ \\
\hline PE/PP R2 & $21.50 \%$ & $78.50 \%$ & $19.89 \%$ & $1.61 \%$ & $70.24 \%$ & $8.26 \%$ & $23.03 \%$ & $-1.53 \%$ & $76.97 \%$ & $1.53 \%$ \\
\hline PE/PP R3 & $40.24 \%$ & $59.76 \%$ & $33.73 \%$ & $6.51 \%$ & $52.92 \%$ & $6.84 \%$ & $40.26 \%$ & $-0.02 \%$ & $59.74 \%$ & $0.02 \%$ \\
\hline PE/PP R4 & $49.49 \%$ & $50.51 \%$ & $45.94 \%$ & $3.55 \%$ & $48.24 \%$ & $2.27 \%$ & $50.17 \%$ & $-0.68 \%$ & $49.83 \%$ & $0.68 \%$ \\
\hline PE/PP R5 & $58.58 \%$ & $41.42 \%$ & $52.81 \%$ & $5.77 \%$ & $36.61 \%$ & $4.81 \%$ & $60.40 \%$ & $-1.82 \%$ & $39.60 \%$ & $1.82 \%$ \\
\hline PE/PP R6 & $81.10 \%$ & $18.90 \%$ & $81.88 \%$ & $-0.78 \%$ & $16.15 \%$ & $2.75 \%$ & $84.28 \%$ & $-3.18 \%$ & $15.72 \%$ & $3.18 \%$ \\
\hline PE/PP R7 & $89.15 \%$ & $10.85 \%$ & $92.01 \%$ & $-2.86 \%$ & $9.54 \%$ & $1.31 \%$ & $91.07 \%$ & $-1.92 \%$ & $8.93 \%$ & $1.92 \%$ \\
\hline
\end{tabular}

Table 4 shows that using the standard enthalpy method, the absolute difference between the test value of PE and the actual value fluctuates between $0.78 \%$ and $6.51 \%$, the mean absolute difference is $3.73 \%$, and the value lies both positive and negative with no law; the absolute difference between the test value of PP and the actual value fluctuates between $1.31 \%$ and $8.26 \%$, and the mean absolute difference is $4.56 \%$, and all the difference values are positive deviation with no law. Using the melting enthalpy normalization method, the absolute difference is between $0.02 \%$ and $3.93 \%$, and the mean absolute difference is $1.87 \%$. It is more accurate when the $\mathrm{PE} / \mathrm{PP}$ content is close, and the difference is larger when the PE/PP content is small. In summary, it can be concluded that the melting enthalpy normalization method is more accurate, related literature [8-10], it may be due to the fact that in the PE/PP blend system, PE and PP are used as separate heterogeneous nucleation crystals, resulting in the crystallinity of the two polymers tending to be the same. the repeatability of polyethylene and polypropylene should not exceed 5\% for the PE/PP blend system.

\subsection{Determination of polyamide 6 and polyamide 66 content in imported recycled plastics}

Weigh appropriate amount of PA6 and PA66, mix and dissolve the mixture with m-toluidine, volatilize the solvent to obtain the PA standard mixture, analysis using the similar steps of PE/PP, and the results are shown in Table 5 and Table 6 :

Table 5 PA6/PA66 standard mixture composition table

\begin{tabular}{|c|c|c|c|c|c|c|c|c|}
\hline No. & Item & PA6, g & PA66, g & $\begin{array}{c}\text { Total } \\
\text { mass } \\
\mathrm{g} \\
\end{array}$ & $\begin{array}{c}\text { Percent of PA6 } \\
\%(\mathrm{~m} / \mathrm{m})\end{array}$ & $\begin{array}{l}\text { Percent of PA66 } \\
\% \%(\mathrm{~m} / \mathrm{m})\end{array}$ & $\begin{array}{l}\text { Melting } \\
\text { Enthalpy } \\
\text { of PA6 }\end{array}$ & $\begin{array}{l}\text { Melting } \\
\text { Enthalpy } \\
\text { of PA66 }\end{array}$ \\
\hline 1 & PA R1 & 4.41 & 0.59 & 5.00 & $88.20 \%$ & $11.80 \%$ & 243.43 & 31.61 \\
\hline 2 & PA R2 & 4.12 & 1.09 & 5.21 & $79.08 \%$ & $20.92 \%$ & 232.99 & 54.73 \\
\hline 3 & PA R3 & 3.39 & 1.62 & 5.01 & $67.66 \%$ & $32.34 \%$ & 173.31 & 77.51 \\
\hline 4 & PA R4 & 2.73 & 2.29 & 5.02 & $54.38 \%$ & $45.62 \%$ & 143.30 & 121.46 \\
\hline 5 & PA R5 & 1.99 & 3.12 & 5.11 & $38.94 \%$ & $61.06 \%$ & 108.98 & 167.51 \\
\hline 6 & PA R6 & 1.28 & 3.73 & 5.01 & $25.55 \%$ & $74.45 \%$ & 59.73 & 189.78 \\
\hline 7 & PA R7 & 0.69 & 4.22 & 4.91 & $14.05 \%$ & $85.95 \%$ & 32.03 & 217.68 \\
\hline
\end{tabular}


Table 6 PA6/PA66 standard mixture composition test results table

\begin{tabular}{|c|c|c|c|c|c|c|c|c|c|c|}
\hline \multirow{3}{*}{$\begin{array}{l}\text { Standard } \\
\text { mixture }\end{array}$} & \multicolumn{2}{|c|}{ Actual ratio } & \multicolumn{4}{|c|}{ Standard enthalpy method } & \multicolumn{4}{|c|}{ Melting enthalpy normalization method } \\
\hline & \multirow{2}{*}{ PA6 } & \multirow{2}{*}{ PA66 } & \multicolumn{2}{|c|}{ PA6 } & \multicolumn{2}{|c|}{ PA66 } & \multicolumn{2}{|c|}{ PA6 } & \multicolumn{2}{|c|}{ PA66 } \\
\hline & & & test & Def. & test & Def. & test & Def. & test & Def. \\
\hline PA R1 & $88.20 \%$ & $11.80 \%$ & $90.65 \%$ & $-2.45 \%$ & $9.30 \%$ & $2.50 \%$ & $88.51 \%$ & $0.31 \%$ & $11.49 \%$ & $0.31 \%$ \\
\hline PA R2 & $79.08 \%$ & $20.92 \%$ & $86.76 \%$ & $-7.68 \%$ & $16.11 \%$ & $4.81 \%$ & $80.98 \%$ & $1.90 \%$ & $19.02 \%$ & $1.90 \%$ \\
\hline PA R3 & $67.66 \%$ & $32.34 \%$ & $64.54 \%$ & $3.13 \%$ & $22.81 \%$ & $9.52 \%$ & $69.10 \%$ & $1.43 \%$ & $30.90 \%$ & $1.43 \%$ \\
\hline PA R4 & $54.38 \%$ & $45.62 \%$ & $53.36 \%$ & $1.02 \%$ & $35.75 \%$ & $9.87 \%$ & $54.12 \%$ & $0.26 \%$ & $45.88 \%$ & $0.26 \%$ \\
\hline PA R5 & $38.94 \%$ & $61.06 \%$ & $40.58 \%$ & $-1.64 \%$ & $49.30 \%$ & $11.75 \%$ & $39.42 \%$ & $0.47 \%$ & $60.58 \%$ & $0.47 \%$ \\
\hline PA R6 & $25.55 \%$ & $74.45 \%$ & $22.24 \%$ & $3.31 \%$ & $55.86 \%$ & $18.59 \%$ & $23.94 \%$ & $1.61 \%$ & $76.06 \%$ & $1.61 \%$ \\
\hline PA R7 & $14.05 \%$ & $85.95 \%$ & $11.93 \%$ & $2.13 \%$ & $64.07 \%$ & $21.88 \%$ & $12.83 \%$ & $1.23 \%$ & $87.17 \%$ & $1.23 \%$ \\
\hline
\end{tabular}

It can be seen from Table 5 and Table 6 that using the standard enthalpy method, the absolute difference between the test value of PA6 and the actual value fluctuates between $1.02 \%$ and $7.68 \%$, and the mean absolute difference is $3.05 \%$, and the values lie both positive and negative with no law. The absolute difference between the test value of PA66 and the actual value fluctuates between $2.50 \%$ and $21.88 \%$, and the mean absolute difference is $11.27 \%$, all the difference values are positive deviation and the deviation gradually increases with the increase of PA66. Using the melting enthalpy normalization method, the absolute difference is between $0.26 \%$ and $1.90 \%$, and the mean absolute difference is $1.03 \%$. In summary, it can be concluded that the melting enthalpy normalization method is more accurate, and for the PA6/PA66 blend system, the repeatability of PA6 and PA66 should not exceed 3\%.

\subsection{Determination of polyolefin and polyamide content in imported recycled plastics}

According to the statistical data of recycled particles imported from major ports in recent years, some recycled plastic particles derived from composite membrane materials may contain both polyethylene and polyamide, two different types of polymers blended. As the recycled particles may come from different batches of film materials, there might be inconsistencies in the composition of the recycled particles, which affects the subsequent use.

Since there is no suitable solvent that can dissolve both PE and PA66 at the same time, physical blending is used to prepare standard samples. Weigh appropriate amount of PE and PA66, mix them with a high-speed mixer, use a small injection moulding machine to inject moulding, and take the standard sample after 10 moulds to test, and analysis using the similar steps of PE/PP. The results are shown in Table 7 and Table 8:

Table 7 PE/PA66 standard mixture composition

\begin{tabular}{|c|c|c|c|c|c|c|c|c|}
\hline No. & Item & PE, $g$ & PA66, g & $\begin{array}{c}\text { Total } \\
\text { mass } \\
\mathrm{g} \\
\end{array}$ & $\begin{array}{c}\text { Percent of PE } \\
\%(\mathrm{~m} / \mathrm{m})\end{array}$ & $\begin{array}{c}\text { Percent of PA66 } \\
\% \%(\mathrm{~m} / \mathrm{m})\end{array}$ & $\begin{array}{c}\text { Melting } \\
\text { Enthalpy } \\
\text { of PE }\end{array}$ & $\begin{array}{l}\text { Melting } \\
\text { Enthalpy } \\
\text { of PA66 }\end{array}$ \\
\hline 1 & PE/PA R1 & 0.52 & 4.45 & 4.97 & 10.46 & 89.54 & 32.29 & 298.34 \\
\hline 2 & PE/PA R2 & 1.03 & 3.94 & 4.97 & 20.72 & 79.28 & 80.35 & 284.75 \\
\hline 3 & PE/PA R3 & 1.93 & 3.04 & 4.97 & 38.83 & 61.17 & 165.84 & 212.24 \\
\hline 4 & PE/PA R4 & 2.47 & 2.58 & 5.05 & 48.91 & 51.09 & 220.83 & 182.46 \\
\hline 5 & PE/PA R5 & 2.97 & 2.05 & 5.02 & 59.16 & 40.84 & 253.81 & 158.45 \\
\hline 6 & PE/PA R6 & 4.05 & 1.06 & 5.11 & 79.26 & 20.74 & 357.03 & 83.18 \\
\hline 7 & PE/PA R7 & 4.53 & 0.50 & 5.03 & 90.06 & 9.94 & 415.51 & 42.55 \\
\hline
\end{tabular}

Table 8 PE/PA66 standard mixture composition test results

\begin{tabular}{|c|c|c|c|c|c|c|c|c|c|c|}
\hline \multirow{3}{*}{$\begin{array}{c}\text { Standard } \\
\text { mixture }\end{array}$} & \multicolumn{2}{|c|}{ Actual ratio } & \multicolumn{4}{|c|}{ Standard enthalpy method } & \multicolumn{4}{|c|}{ Melting enthalpy normalization method } \\
\hline & \multirow{2}{*}{$\mathrm{PE}$} & \multirow{2}{*}{ PA66 } & \multicolumn{2}{|c|}{$\mathrm{PE}$} & \multicolumn{2}{|c|}{ PA66 } & \multicolumn{2}{|c|}{$\mathrm{PE}$} & \multicolumn{2}{|c|}{ PA66 } \\
\hline & & & test & Def. & test & Def. & test & Def. & test & Def. \\
\hline PE/PA R1 & $10.46 \%$ & $89.54 \%$ & $6.58 \%$ & $3.88 \%$ & $84.84 \%$ & $4.70 \%$ & $9.77 \%$ & $0.70 \%$ & $90.23 \%$ & $-0.70 \%$ \\
\hline PE/PA R2 & $20.72 \%$ & $79.28 \%$ & $16.39 \%$ & $4.34 \%$ & $80.97 \%$ & $1.70 \%$ & $22.01 \%$ & $-1.28 \%$ & $77.99 \%$ & $1.28 \%$ \\
\hline PE/PA R3 & $38.83 \%$ & $61.17 \%$ & $33.82 \%$ & $5.01 \%$ & $60.35 \%$ & $0.81 \%$ & $43.86 \%$ & $-5.03 \%$ & $56.14 \%$ & $5.03 \%$ \\
\hline PE/PA R4 & $48.91 \%$ & $51.09 \%$ & $45.03 \%$ & $3.88 \%$ & $51.88 \%$ & $0.79 \%$ & $54.76 \%$ & $-5.85 \%$ & $45.24 \%$ & $5.85 \%$ \\
\hline PE/PA R5 & $59.16 \%$ & $40.84 \%$ & $51.76 \%$ & $7.40 \%$ & $45.06 \%$ & $4.22 \%$ & $61.57 \%$ & $-2.40 \%$ & $38.43 \%$ & $2.40 \%$ \\
\hline PE/PA R6 & $79.26 \%$ & $20.74 \%$ & $72.81 \%$ & $6.45 \%$ & $23.65 \%$ & $2.91 \%$ & $81.10 \%$ & $-1.85 \%$ & $18.90 \%$ & $1.85 \%$ \\
\hline PE/PA R7 & $90.06 \%$ & $9.94 \%$ & $84.73 \%$ & $5.33 \%$ & $12.10 \%$ & $2.16 \%$ & $90.71 \%$ & $-0.65 \%$ & $9.29 \%$ & $0.65 \%$ \\
\hline
\end{tabular}


It can be seen from Table 7 and Table 8 that using the standard enthalpy method, the absolute difference between the test value of PE and the actual value fluctuates between $3.88 \%$ and $7.40 \%$, the mean absolute difference is $5.18 \%$, and all the difference values are positive deviation with no law. The absolute difference between the test value of PA66 and the actual value fluctuates between $0.79 \%$ and $4.70 \%$, and the mean absolute difference is $2.47 \%$, and all the difference values are positive deviation with no law. Using the melting enthalpy normalization method, the absolute difference is between $0.65 \%$ and $5.85 \%$, and the mean absolute difference is $2.54 \%$. And the difference is larger when the PE/PA66 content is close, and it's smaller when the PE/PA66 content is small. In summary, it can be concluded that the melting enthalpy normalization method is more accurate, and for the PE/PA blend system, the repeatability of $\mathrm{PE}$ and $\mathrm{PA}$ should not exceed $6 \%$.

\section{Conclusions}

Based on the test results of above LDPE/LLDPE/HDPE, PE/PP blends, PA6/PA66 blends, PE/PA blends and other common polymers that are easy to blend, the difference between the results of the standard enthalpy method and the actual results is large. This method is required to use a polymer similar to the source to calibrate the standard enthalpy value. Its operability is poor as it also takes multiple tests. The melting enthalpy normalization method directly uses the melting enthalpy of the polymer in the sample for calculation, which has the advantages of simple and fast operation, and the absolute difference between the test results and the actual results is within the controllable range. So the melting enthalpy normalization method is chosen to test the polymer composition in plastic solid waste samples. This method can effectively and quickly determine the composition of crystalline recycled plastics.

\section{Acknowledgements}

This work was financially supported by the science research project of General Administration of Customs, P. R. CHINA (Fund No.: 2019HK016 and 2020HK245), the Ningbo public science research project (Fund No.: 2019C50031) and the Zhejiang basis public science research project (Fund No.: LGC20B040001).

\section{References}

1. DONG YM, XIONG XP, ZHENG W, etc. (2011) GAOFENZI YANJIU FANGFA. China Petrochemical Press Co. LTD, Beijing. China

2. YANG L, ZHOU ZC, YAO ZP, etc., (2019) Qualitative and quantitative analysis for PA6/PA66 compounds and co-polymers. CHINA SYNTHETIC RESIN AND PLASTICS. 36(2):7-9,18

3. YUAN LF, LUO C, XU SH, etc., (2020) Quantitative analysis of blend ratio of polycarbonate to acrylonitrile-butadiene-styrene copolymer by pyrolysis gas chromatography - mass spectrometry using solid dispersant for sample preparation, Journal of Instrumental Analysis 39(6):69-773

4. ZHANG Y, LUO C, YUAN LF, etc. (2021) Pyrolysis-gas chromatography-mass spectrometry to identification of the solid waste characteristic of imported polyamide recycled plastics. Earth Environ. Sci. 621(2021)012038

5. ZHOU MY, YAN LK, JIAO GY. combined test metbcd with IR and DSC for plastics. Plastics SCI. \& Technology. 125(3):47-52

6. General Administration of Quality Supervision, Inspection and Quarantine of the People's Republic of China and Standardization Administration of the People's Republic of China and Standardization administration. (2004) Plastics - Differential scanning calorimetry (DSC) - Part 1: General principles: GB/T 19466.1-2004. Standards Press of China, Beijing.

7. General Administration of Quality Supervision, Inspection and Quarantine of the People's Republic of China and Standardization Administration of the People's Republic of China and Standardization administration. (2004) Plastics - Differential scanning calorimetry (DSC) - Part 3: Determination of temperature and enthalpy of melting and crystallization: GB/T 19466.3-2004. Standards Press of China, Beijing.

8. LI XJ, LIAO MY, ZHANG Y, etc. (2006) Study on crystallization and melting processes of nPP. Contemporary Chemical Industry. 35(3) :153-156

9. LIU YX, YANG Q, ZHAO L, etc. (2006) Study on crystallization behaviour of LLDPE/BR, LLDPE/PP by SALS. CHINA PLASTICS INDUSTRY. 34(2):48-51

10. GONG CH, SUN H, SHENG J. () Progress in Studies of the crystallization behaviors of the crystal polymer in two components blend. Chinese Polymer Bulletin. $7: 72-76,81$ 